\title{
LO QUE CUENTA PARA LOS RANKIGS UNIVERSITARIOS EN INVESTIGACIÓN.
}

\author{
Por: Dr. Gabriel Peña Rodríguez. \\ Profesor Titular UFPS
}

Actualmente los sistemas de educación superior de muchos países publican listas de sus instituciones de educación superior (IES) o universidades, ordenadas de mayor a menor según algunos criterios de calidad, lo anterior es conocido como los rankings universitarios. Según el diccionario de la Real Academia Española de la Lengua, la palabra "ranking" es un extranjerismo que significa "clasificación de mayor a menor, útil para establecer criterios de valoración”. Dichos listados (rankings), cada día toman auge, donde el uso de plataformas tecnológicas y sistemas de información, permiten valorar indicadores en tiempo real, que según los modelos usados miden y clasifican a las universidades o IES. Lo anterior no es un fenómeno nuevo, por ejemplo, el psicólogo James McKeen, sugirió en 1910 clasificar las universidades, según el número de investigadores con amplia trayectoria científica que formara parte del claustro docente de dicha universidad.

A la fecha existe un gran número de ranking o sellos de calidad de universidades como Quaquarelli Symonds (QS), Scimago, webometrics, U-Sapiens entre otros, donde dicha clasificación en teoría son sinónimo de calidad, que refleja los esfuerzos de las universidades por mejorar sus indicadores en materia de investigación (revistas científicas indexadas, grupos de investigación, publicaciones científicas en revistas con altos factores de impacto, etc...), formación de recurso humano (programas de maestría y doctorado de alto nivel) y empleabilidad de sus egresados entre otros, contribuyendo a los procesos de internacionalización y visibilidad.

Según el ranking web de universidades(http://www.webometrics.info/es), a la fecha de un total de 289 universidades o IES en Colombia, la Universidad Francisco de Paula Santander ocupa el lugar 72, donde la Universidad Nacional de Colombia ocupa el primer lugar. Mientras que los reportes de los rankings U-Sapiens, que utiliza en su modelo de medición indicadores como: el número total de revistas indexadas en el Índice Bibliográfico Nacional(IBN-Publindex), número total de programas activos de maestría y doctorado, y número total de investigadores y grupos de investigación categorizados por Colciencias, la universidad Francisco de Paula Santander según el primer listado de 2017, paso de ocupar el lugar 89 al 65, subiendo 24 puestos en este ranking (https://www.srg.com.co/usapiens.php). Lo anterior es un reflejo del compromiso de la comunidad académica, al cumplimiento de las políticas de acreditación de alta calidad impulsada por la actual administración.

En general podemos afirmar que lo que cuenta para los rankings universitarios en investigación son bien claros y definidos: cantidad de revistas indexadas, cantidad de programas activos de maestría y doctorados, cantidad de grupos e investigadores categorizados por Colciencias, cantidad de patentes registradas, cantidad de citas (índice h) de las publicaciones de sus investigadores, y empleabilidad de sus egresados entre otros. 